\title{
Determination of heat transfer intensity between free streaming water film and rigid surface using thermography
}

\author{
by S. Švaić, I. Boras and M. Suša
}

Faculty of mechanical engineering and naval architecture University of Zagreb, Croatia

\begin{abstract}
The goal of the research was to find the relation for determining the heat transfer coefficient between a free streaming water film and metal corrugated surface. The relation between relevant parameters which determine the heat transfer coefficient has been obtained by means of Wilson-plot method using data from the measurement.
\end{abstract}

\section{Introduction}

The open plate heat exchanger (OPHE) consists of two plates welded together so that one stream is flowing between plates and another one over the outer surface of upper plate. The aim of such heat exchanger design is to enable the heat exchange between outer stream which could be waste dirty water and inner stream. The OPHE are often used for heat recovery purposes in laundries, paper industries etc. The main problem in thermo dynamical calculation of such type of heat exchanger is determination of the heat transfer coefficient on outer side. Because the plates are always inclined to the horizontal plane and outer surface is corrugated to ensure better heat transfer the standard relations for flat plate could not be used. The paper presents the results of the research done on the one plate of OPHE with the aim to find the relation for heat transfer coefficient between streaming film and plate. The IR thermography was used for measurements of temperature distribution on water film streaming over the outer plate surface.

\section{The problem}

The open plate heat exchanger is aimed for heat exchange between hot waste water stream and cold fresh water stream. Waste water flows over the outer (upper) side of the OPHE plate in free stream and fresh water flows inside, between the plates. OPHE are used in the case when waste water contents particles or coagulants. The advantage of such construction is the possibility of easy cleaning of the plates and module design which enables enlargement of the unit. The upper side of OPHE plate is corrugated to improve the heat exchange between free stream of waste water and plate. The OPHE plates are inclined $\left(5^{\circ}\right)$ to horizontal plane to ensure the free streaming by means of gravity. While the equations for calculating the heat transfer coefficient inside the plates could be find in literature the relation for calculation the heat transfer coefficient on outer side became a problem. The goal of the research was to find the relation for determination the heat transfer coefficient on the outer side of the OPHE plate.

The single plate of OPHE used in experiment is shown on figure 1 and the detail of corrugated upper surface on figure 2. 

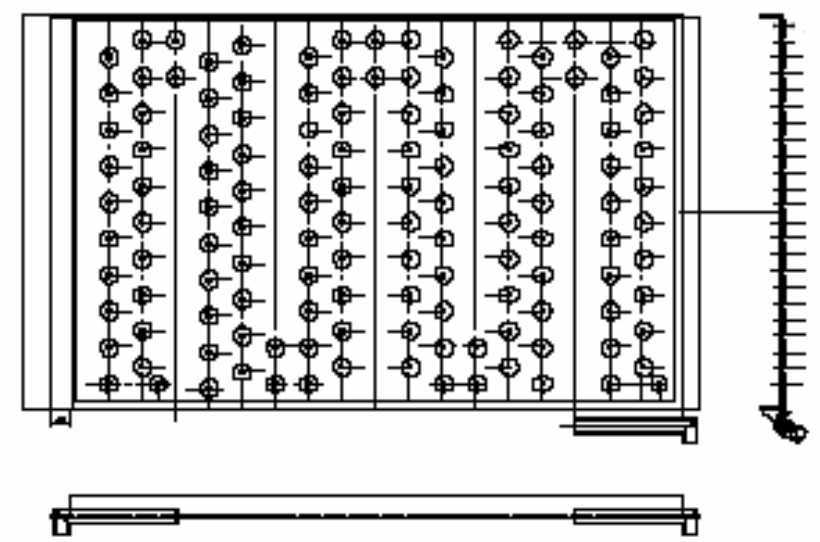

Fig. 1. The plate of heat exchanger

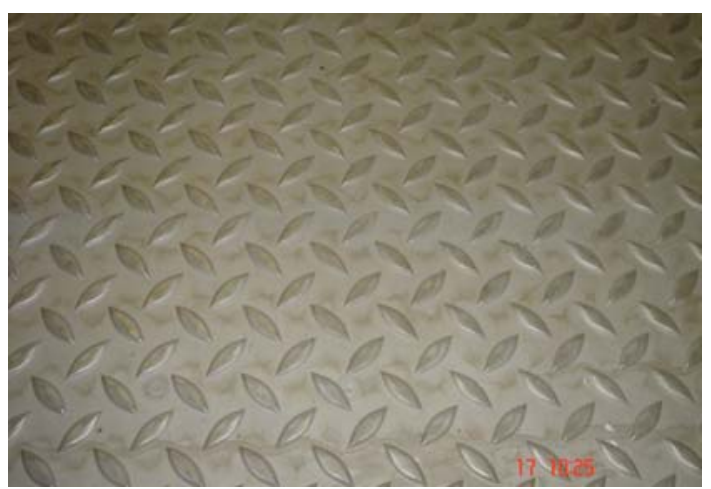

Fig. 2. The features of upper plate

\section{Experimental rig}

The experimental rig consists of single OPHE plate placed on frame with upper and lower container (see figure 3). The hot waste water enters the upper container and overflow on the plate. After passing the plate the water enters the lower container. The fresh water streams in counter flow between the plates. 


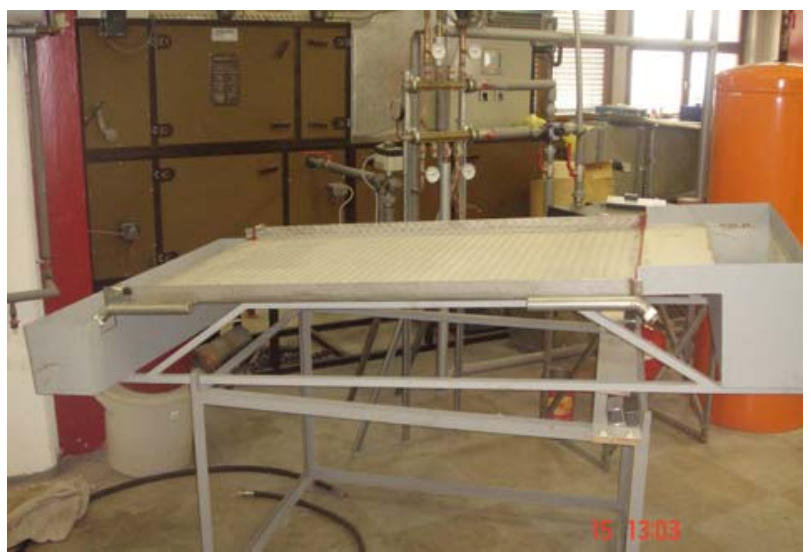

Fig. 3. Experimental rig

The mass flow of waste (hot) and fresh (cold) water are measured by weighing while the temperatures are measured by thermocouples (see figure 4). Beside the thermocouples the surface temperature distribution of hot water streaming over the plate was recorded by IR camera. All measurements were done in stationary state.

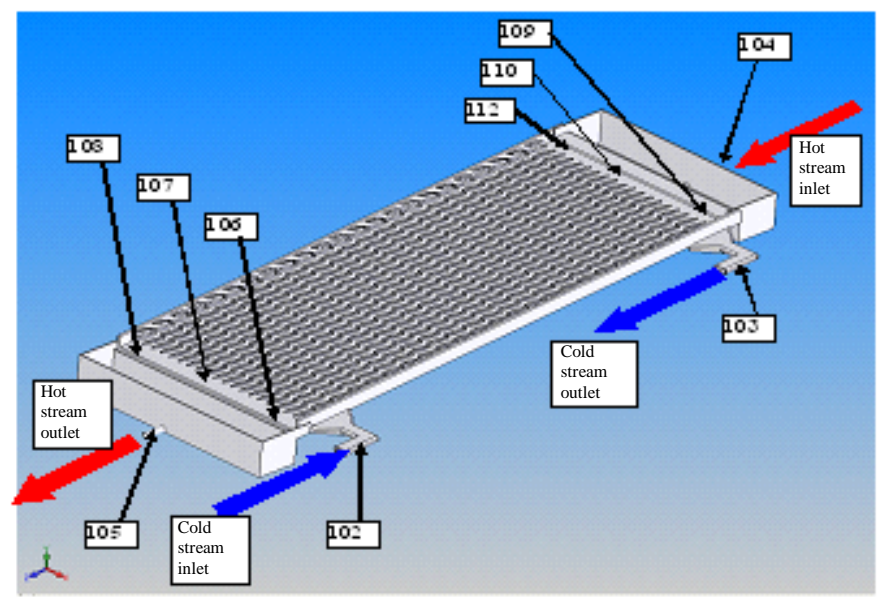

Fig. 4. Positions of thermocouples and directions of hot and cold water stream

\section{Measurements}

The measurements were carried out with mass flow of 0,$1 ; 0,2 ; 0,3$ and 0,4 $\mathrm{kg} / \mathrm{s}$ for hot stream and 0,1 and $0,2 \mathrm{~kg} / \mathrm{s}$ for cold stream. Some of the results are presented in table 1 and the related thermograms are shown on figure 5. 
http://dx.doi.org/10.21611/qirt.2006.061

Table 1. The results of measurement using thermocouples

\begin{tabular}{|c|l|c|c|}
\hline $\begin{array}{l}\text { Measurement } \\
\text { No. }\end{array}$ & & Hot stream & Cold stream \\
\hline \multirow{3}{*}{1} & Mass flow $[\mathrm{kg} / \mathrm{min}]$ & 12,58 & 6,31 \\
\cline { 2 - 4 } & Inlet temperature $\left[{ }^{\circ} \mathrm{C}\right]$ & 25,67 & 12,57 \\
\cline { 2 - 4 } & Outlet temperature $\left[{ }^{\circ} \mathrm{C}\right]$ & 19,59 & 21,93 \\
\hline \multirow{3}{*}{2} & Mass flow $[\mathrm{kg} / \mathrm{min}]$ & 5,03 & 12,48 \\
\cline { 2 - 4 } & Inlet temperature $\left[{ }^{\circ} \mathrm{C}\right]$ & 43,54 & 13,47 \\
\cline { 2 - 4 } & Outlet temperature $\left[{ }^{\circ} \mathrm{C}\right]$ & 15,31 & 23,65 \\
\hline \multirow{3}{*}{3} & Mass flow $[\mathrm{kg} / \mathrm{min}]$ & 12 & 12,14 \\
\cline { 2 - 4 } & Inlet temperature $\left[{ }^{\circ} \mathrm{C}\right]$ & 27,29 & 13,72 \\
\cline { 2 - 4 } & Outlet temperature $\left[{ }^{\circ} \mathrm{C}\right]$ & 18,23 & 21,21 \\
\hline \multirow{3}{*}{4} & Mass flow $[\mathrm{kg} / \mathrm{min}]$ & 24,5 & 12,25 \\
\cline { 2 - 4 } & Inlet temperature $\left[{ }^{\circ} \mathrm{C}\right]$ & 21,90 & 15,11 \\
\cline { 2 - 4 } & Outlet temperature $\left[{ }^{\circ} \mathrm{C}\right]$ & 19,07 & 19,61 \\
\hline
\end{tabular}

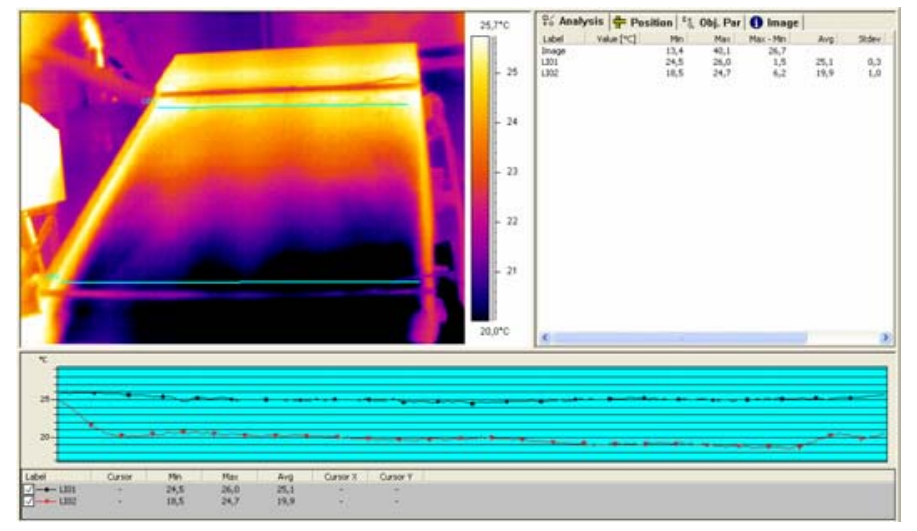

a) Measurement No.1 
http://dx.doi.org/10.21611/qirt.2006.061

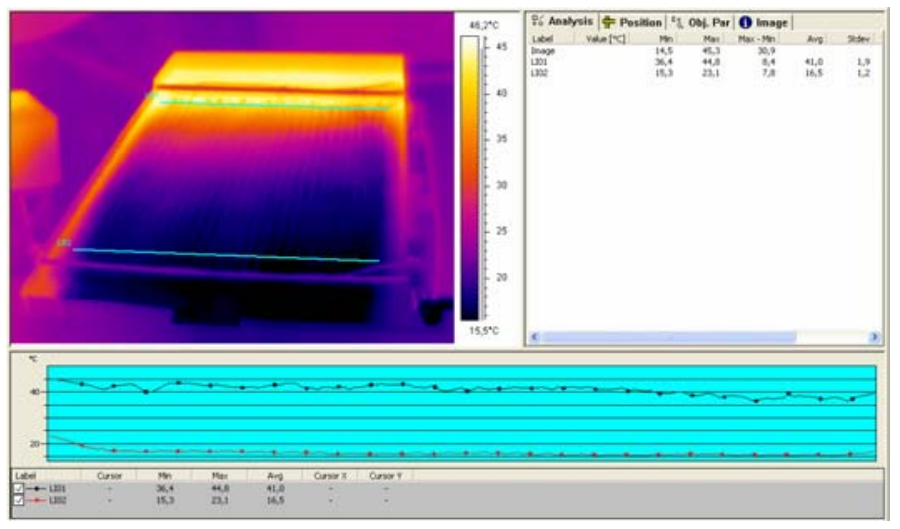

b) Measurement No. 2

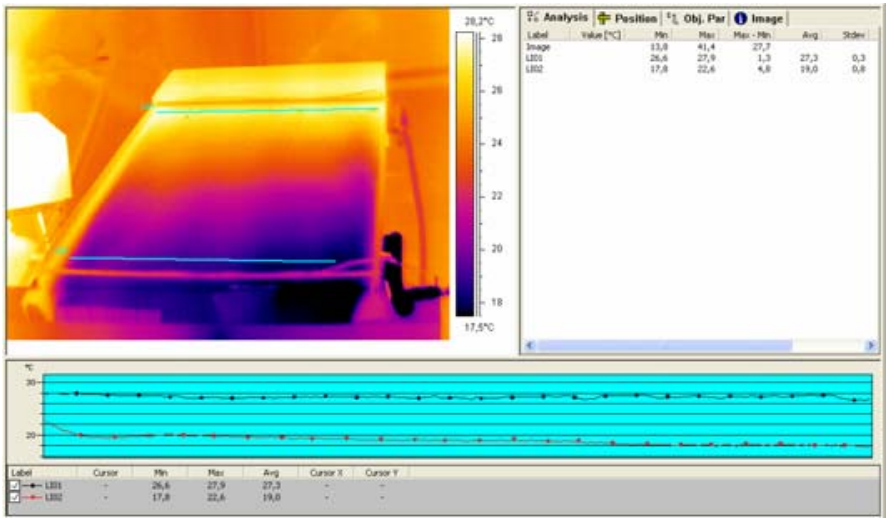

c) Measurement No.3

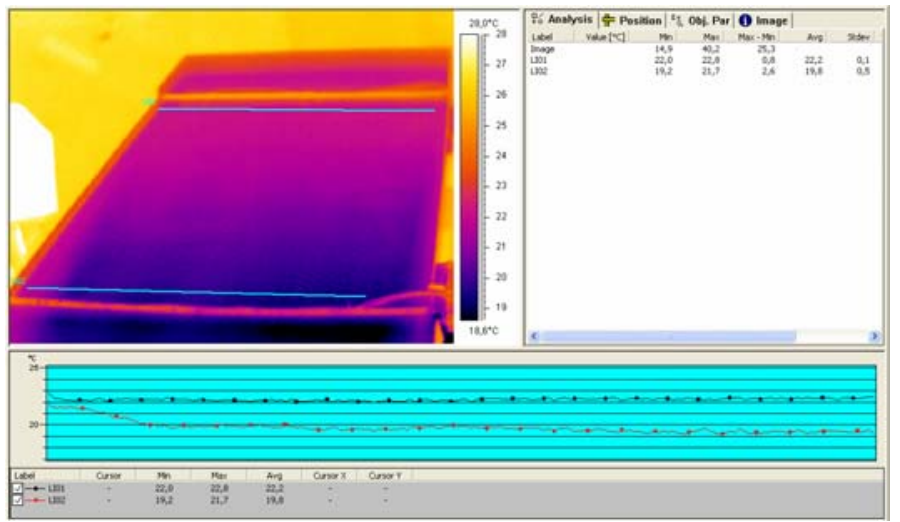

d) Measurement No.4

Fig. 5. Thermograms and referent temperatures 
The heat exchanged between the streams was calculated using relations: - for hot stream

$$
\begin{aligned}
& \Phi_{h}=q_{h} \cdot c_{h} \cdot\left(\vartheta_{i h}-\vartheta_{o h}\right) \mathrm{kW} \\
& \text { - for cold stream } \\
& \Phi_{c}=q_{c} \cdot c_{c} \cdot\left(\vartheta_{o c}-\vartheta_{i c}\right) \mathrm{kW}
\end{aligned}
$$

Table 2. The comparison of measurement's results

\begin{tabular}{|c|c|c|c|}
\hline $\begin{array}{l}\text { Measurement } \\
\text { No. }\end{array}$ & \multicolumn{1}{|l|}{$\begin{array}{l}\Phi_{\mathrm{c}} \\
\mathrm{kW}\end{array}$} & $\begin{array}{l}\Phi_{\mathrm{h} \text { thermocouples }} \\
\mathrm{kW}\end{array}$ & $\begin{array}{l}\Phi_{\mathrm{h} \mathrm{IR}} \\
\mathrm{kW}\end{array}$ \\
\hline 1 & 4,119 & 5,327 & 4,55 \\
\hline 2 & 8,861 & 9,883 & 8,59 \\
\hline 3 & 6,343 & 7,580 & 6,68 \\
\hline 4 & 3,845 & 4,843 & 4,09 \\
\hline
\end{tabular}

It can be seen that, using recordings by infrared camera, better accuracy was obtained for hot water stream in comparison with those obtained by thermocouples.

\section{Results}

By means of overall heat transfer coefficients, calculated from measurement, and heat transfer coefficient for cold stream using Eq. (3), the heat transfer coefficient for hot stream has been determined using Eq. (4).

$$
\begin{aligned}
& \alpha_{c}=0,022 \cdot \operatorname{Re}^{0,8} \cdot \operatorname{Pr}^{0,4} \cdot \frac{\lambda}{d_{e k v}} \\
& \frac{1}{\alpha_{h}}=\frac{1}{k}-\frac{\delta_{\text {wall }}}{\lambda_{\text {wall }}}-\frac{1}{\alpha_{c}}
\end{aligned}
$$

Using Wilson-plot method the relation Eq. (5) for determination of heat transfer coefficient of outer stream can be found using data from measurements:

$$
\alpha_{h}=0,524 \cdot \operatorname{Re}^{0,74} \cdot \operatorname{Pr}^{1 / 3} \cdot \frac{\lambda}{L}
$$

Calculating the heat transfer coefficient using Eq. (5) for hot stream and comparing them with those obtained from measurement it can be seen that good mutual correspondence is obtained (see table 3).

Table 3. The comparison of heat transfer coefficients for hot stream; measurement and Eq.(5)

\begin{tabular}{|c|l|l|}
\hline $\begin{array}{l}\text { Measurement } \\
\text { No. }\end{array}$ & $\begin{array}{l}\alpha_{\text {from }} \\
\text { measurement } \\
\mathrm{W} / \mathrm{m}^{2} \mathrm{~K}\end{array}$ & $\begin{array}{l}\alpha_{\text {calculated }} \\
\text { Eq.(5) } \\
\mathrm{W} / \mathrm{m}^{2} \mathrm{~K}\end{array}$ \\
\hline 1 & 2892,7 & 2866,3 \\
\hline 2 & 2337,4 & 2286,5 \\
\hline 3 & 2914,5 & 2832,0 \\
\hline 4 & 3232,8 & 3376,5 \\
\hline
\end{tabular}


http://dx.doi.org/10.21611/qirt.2006.061

\section{Conclusion}

In the paper the application of IR thermography in determination of heat transfer intensity has been described. The specific profile of heat exchanger's surface required an investigation for new relations for calculation of heat transfer coefficients. The results obtained using Eq.(5) for calculation heat transfer coefficients on hot water side indicated a good correspodence with the measurement's result.

\section{REFERENCES}

[1] D.P.ALMOND, P.M.PATEL, Photothermal Science and Technique, London, Chapman \& Hall, 1996.

[2] S.V. PATANKAR, Numerical Heat Transfer and Fluid Flow, Hemisfere Publishing Corporation, Mc Grow-Hill Book Co, Washington, 1980.

[3] Gerald C. Holst, Common sense approach to thermal imaging, SPIE Optical Engeenering Press, Bellingham, Washington, USA, 2000 